\title{
The effect of manipulating growth in sheep by diet or anabolic agents on plasma cortisol and muscle glucocorticoid receptors
}

\author{
BY P. M. SHARPE, P. J. BUTTERY* AND N. B. HAYNES \\ University of Nottingham School of Agriculture, Sutton Bonington, \\ Loughborough, Leics LE12 SRD
}

(Received 8 July 1985 - Accepted 24 February 1986)

\begin{abstract}
1. The cortisol status (total plasma cortisol concentration, free cortisol concentration, transcortin capacity) and the characteristics of skeletal muscle binding for cortisol and dexamethasone were examined in female lambs either implanted with Zeranol or trenbolone acetate or whose dietary intake was restricted.

2. The skeletal muscle glucocorticoid receptor had a high affinity for the glucocorticoid triamcinolone (relative binding affinity 0.85 ) and cortisol (relative binding affinity 0.51 ) with virtually no affinity for trenbolone.

3. Trenbolone acetate treatment reduced the binding capacity of sheep skeletal muscle for cortisol within $2 \mathrm{~d}$ of implantation. The other treatments had little effect except a small reduction in the animals where food intake was restricted. Similarly, binding capacity for dexamethasone was reduced by trenbolone acetate treatment but was not affected by the other treatments. This reduction in trenbolone acetate-treated animals is, at least in part, due to a reduction in glucocorticoid receptors.

4. Transcortin capacity was elevated by Zeranol treatment but reduced with diet restriction or trenbolone treatment.

5. No support for the suggestion of free cortisol concentration being important in the growth-promoting mechanism of trenbolone or Zeranol was obtained.

6. Although insulin concentrations were not significantly altered by treatment $(P>0.05)$, when combining all the animals there was evidence of a negative correlation between total cortisol:insulin vaue $(P<0.05)$ or free cortisol:insulin value and growth rate $(P<0.001)$. Free cortisol was negatively correlated to growth rate $(P<0.05)$ and transcortin capacity positively correlated $(P<0.01)$.
\end{abstract}

Since, in general, glucocorticoids have a catabolic effect on protein metabolism in muscle (cf. review by Buttery, 1983) it might be expected that high circulating concentrations of such steroids would result in slower growth rates. Certainly in children with abnormally high levels of cortisol low growth rates occur, and adults in a similar situation are subject to muscle atrophy (McGrath \& Goldspink, 1982). In ruminant species much of the published information is equivocal. A negative relation between glucocorticoid concentrations and growth rate has been reported several times in cattle (Purchas et al. 1971; Trenkle \& Topel, 1978), but other studies failed to confirm this (Lange \& Lindermann, 1972). In sheep, there have been reports of no relation (Purchas et al. 1980), a positive relation (Purchas, 1973; although the increased growth in this case was probably due to an increase in carcass fat content) and also the possibility that the anabolic agent, trenbolone acetate (TBA), may act by reducing adrenal function (Thomas \& Rodway, 1983a). The latter workers also demonstrated a similar phenomenon in rats (Thomas \& Rodway, 1983b).

The main problems encountered in the investigation of the role of cortisol, the major circulating glucocorticoid in ruminants, in growth are first the episodic nature of cortisol release, and the need to determine the fraction of putatively physiologically active cortisol, i.e. that not bound to plasma proteins such as transcortin. Barnett \& Star (1981), taking account of these problems, found a significant negative correlation between unbound plasma cortisol (free cortisol) and weight change in sheep; however, this was in a complex situation using recently parous sheep, some of which were suckling lambs. Second, the presence of high-affinity corticosteriod-binding components distinct from transcortin has been found in several tissues (Feldman et al. 1973; Giannopoulus, 1973; Markovic et al.

* For reprints. 
1980). Specifically, the presence of a skeletal-muscle glucocorticoid receptor has been shown in a variety of species, namely the rat (Mayer et al.1974), pig (Snochowski et al. 1981) and human (Snochowski et al. 1980 b) and in some cases this has been extensively characterized (Snochowski et al. 1980a). Most of these studies have used the synthetic glucocorticoid dexamethasone as the ligand, since this compound binds to the cytosolic receptor but not to any possible contaminating plasma proteins such as transcortin (Pugeat et al. 1981). Third, there is the possibility of an interaction between corticosteroids and other hormones in relation to growth effects. For instance, working mainly with diabetic animals, Odedra \& Millward (1982) and Odedra et al. (1982) have reported a direct antagonism between glucocorticoids and insulin in their effects on muscle protein synthesis.

The present paper presents findings concerning the relation between total, transcortinbound and free cortisol concentrations and growth rate in the growing female lamb, growth rate being manipulated in a variety of ways, i.e. by treatment with TBA (an anabolic steriod with androgenic activity), Zeranol (an anabolic agent with oestrogenic activity) or by diet restriction. It further describes the effect of such treatments on the concentration of glucocorticoid receptors in skeletal muscle. Cortisol and dexamethasone were used as the ligands in receptor studies and the results obtained with each ligand were compared. Insulin was also measured in plasma samples, along with cortisol in a preliminary investigation, to determine whether those hormones had interactions in modulating the growth response.

\section{MATERIALS AND METHODS}

$\left[1,2,6,7-{ }^{3} \mathrm{H}\right]$ Cortisol $(91 \mathrm{Ci} / \mathrm{mmol}),\left[1,2,4,6,7-{ }^{3} \mathrm{H}\right]$ dexamethasone $(78 \mathrm{Ci} / \mathrm{mmol})$ and the insulin assay kit were obtained from Amersham International plc, Amersham, Bucks. Unlabelled steroids: cortisol, dexamethasone, oestradiol-17 $\beta$, testosterone, corticosterone and trenbolone were obtained from Sigma Chemical Co., Poole, Dorset; Zeranol $(6-(6,10$ dihydro-oxyundecyl) $\beta$-resorcyclic acid- $\mu$-lactone) from Crown Chemicals (Kent); and TBA (3-oxo-17 $\beta$-hydroxy-4,9,11-oestratriene acetate) as the preparation Finaplix from Hoechst UK, Hounslow, Middlesex.

\section{First growth trial}

Thrity-two female Suffolk $\times$ Clun Forest lambs aged approximately 3 months were used. These animals were divided into four treatment groups with eight lambs in each. The four groups were: a control group and two groups implanted subcutaneoulsy in the upper surface of the ear with an anabolic agent; one group with Zeranol $(12 \mathrm{mg} / \mathrm{lamb})$; one with TBA $(60 \mathrm{mg} / \mathrm{lamb})$. Each of these groups was fed $a d$ lib. on a fattening diet consisting of $(\mathrm{kg} / 1000 \mathrm{~kg}$ ): barley 550 , oats 350 , soya-bean meal 25 , molassed peat (Rumenco Ltd, Burton on Trent) 50, Wrightmin Sheep Mix (Frank Wright Ltd, Ashbourne) 25. The metabolizable energy of the diet was calculated to be $12 \cdot 1 \mathrm{MJ} / \mathrm{kg}$ and the crude protein (nitrogen $\times 6.25$ ) content was $114 \mathrm{~g} / \mathrm{kg}$. The fourth group was fed on a restricted diet of approximately $500 \mathrm{~g} / \mathrm{d}$ of the same feed. This amount was estimated to provide a metabolizable energy for maintenance and not growth. All sheep were kept in individual pens in a completely randomized design. The animals were allowed to adapt to their new environment for 2 weeks before any experimentation took place. During this period the animals were subjected to routine procedures such as feeding, cleaning and weighing. After this the three treatment groups were either implanted or placed on the restricted diet, and all animals were weighed. The animals were then weighed at weekly intervals throughout the course of the experiment and food intake was monitored.

After $25 \mathrm{~d}$ the sheep were cannulated via the jugular vein and were weighed; $48 \mathrm{~h}$ later a $26 \mathrm{~h}$ blood-sampling regimen was carried out on all the animals. Beginning at 07.00 hours, 
$7 \mathrm{ml}$ blood samples were taken at 30 -min intervals for $26 \mathrm{~h}$. The heparinized blood samples were immediately centrifuged at $1500 \mathrm{~g}$ for $5 \mathrm{~min}$ at $4^{\circ}$ and the resulting plasma was stored at $-15^{\circ}$. The samples taken for the first $2 \mathrm{~h}$ were to accustom the sheep to the bleeding procedures and to allow for any initial rise in cortisol levels due to stress, and these samples were not included in the final analysis.

Approximately $3 \mathrm{~d}$ after the bleed had been completed the sheep on the anabolic-agent treatments were re-implanted. In the week subsequent to bleeding some of the animals were observed to have reduced their feed intake leading to a small weight loss. At 2 weeks after re-implantation any animal whose food intake was less than that before the bleed and was not gaining weight, was removed from the trial. After a further 2 weeks the animals which were eating and growing normally were slaughtered and sections of the longissimus dorsi were removed and stored at $-40^{\circ}$. Because of the problems with this trial the effects of TBA were studied further in a second trial.

\section{Second growth trial}

The animals used were twenty Dorset Horn female lambs aged approximately 2 months. These animals were divided randomly into two treatment groups with ten lambs in each: a control group and a group implanted in the ear with TBA $(60 \mathrm{mg} / \mathrm{lamb})$. Both groups were fed ad lib. on a fattening diet (composition as in the first growth trial). The animals were placed in individual pens for a 3-week adaptation period. After this the TBA-treatment group was implanted, and throughout the experiment the animals were weighed at weekly intervals.

At $1 \mathrm{~d}$ after implantation two animals from each group, selected at random, were slaughtered and sections of the longissimus dorsi were removed and stored at $-40^{\circ}$. This procedure was repeated at 8,15 and $22 \mathrm{~d}$ after implantation, the exception being that four animals from each treatment group were taken at the $15 \mathrm{~d}$ slaughter date.

\section{Hormone assays}

In each of the hormone assays the plasma sample used was a pooled sample formed by taking a standard volume of each individual blood sample from one animal and pooling them together. The value obtained for each sample is thus the average value of hormone concentration for that animal over the $24 \mathrm{~h}$ of the bleed.

Total cortisol concentrations were assayed using antiserum and the method described by Morris (1978) with the following modifications. Portions of sheep plasma $(10 \mu \mathrm{l})$ were made up to $100 \mu \mathrm{l}$ with assay buffer and extracted by shaking for $20 \mathrm{~min}$ with diethyl ether rather than inactivating the cortisol-binding globulin by heat treatment. The aqueous layer was frozen and the diethyl ether decanted and evaporated to dryness. The extracted cortisol was then reconstituted in $100 \mu \mathrm{l}$ buffer for assay. Recovery of added radioactive cortisol by diethyl ether extraction was $90 \%$. Sensitivity of the assay ( $2 \mathrm{SD}$ ) of the standard curve point containing zero cortisol was $0.8 \mathrm{ng} / \mathrm{ml}$ plasma. Assay of low-cortisol plasma after the addition of $62 \cdot 5,125$ and $250 \mathrm{pg}$ cortisol gave recoveries (\%) of 109 (SD 8), 102 (SD 4) and 105 (SD 2) respectively (six replicates in each case). Assay of 5, 10 and $20 \mu 1$ of a plasma containing $29 \mathrm{ng}$ cortisol $/ \mathrm{ml}$ demonstrated parallelism with the standard curve. The inter-assay coefficient of variation of a control plasma pool was $9.1 \%$ and the intra-assay coefficient of variation was $8.2(\mathrm{SD} 2.9) \%$. The maximum cortisol-binding capacity as a measure of transcortin concentration was determined by the method of Pegg \& Keane (1969). As suggested by Barnett \& Star (1981), by assuming a high-affinity binding constant of $0.87 \times 10^{8} \mathrm{l} / \mathrm{mol}$ at $37^{\circ}$ and an albumin bound : free value of 0.825 as determined for sheep (Paterson \& Hills, 1967), the concentration of free cortisol in the plasma was calculated 
(Tait \& Burstein, 1964). The recovery of unlabelled cortisol added to plasma was $99 \cdot 2$ (SD $11 \cdot 6) \%$.

Insulin concentrations were estimated using an RIA kit obtained from Amersham International. The inter-assay coefficient of variation was found to be $12.1 \%$ and the intra-assay coefficient of variation was less than $6 \%$.

\section{Receptor analysis}

Preparation of cytosol. This was essentially carried out as described by Vernon et al. (1974). All procedures were carried out at $0-4^{\circ}$. Muscle was homogenized using a Polytron homogenizer (Kinematica, Lucerne, Switzerland) in 1:3 (w/v) $10 \mathrm{~mm}$-Tris-hydrochloride buffer (pH 7.4) containing 2 mM-EDTA, $1 \mathrm{~mm}$-dithiothreitol and $100 \mathrm{~mm}$-potassium chloride. The homogenate was centrifuged at $105000 \mathrm{~g}$ for $1 \mathrm{~h}$. A portion of the resulting supernatant fraction was removed for protein determination by the method of Lowry et al. (1951). The remainder of the supernatant fraction was treated with $100 \mathrm{ml}$ glycerol/1 and $250 \mathrm{ml} /$ dextran-coated charcoal suspension (100 $\mathrm{g}$ charcoal $/ 1,10 \mathrm{~g}$ dextran $/ 1) / 1$ and was incubated at $4^{\circ}$ for $15 \mathrm{~min}$. The mixture was then centrifuged at $10000 \mathrm{~g}$ for $10 \mathrm{~min}$. The freshly prepared supernatant fraction was used as cytosol in subsequent experiments.

Time-course for $\left[{ }^{3} \mathrm{H}\right]$ cortisol and $\left[{ }^{3} \mathrm{H}\right]$ dexamethasone binding. The method used was essentially that of Snochowski et al. $(1980 \mathrm{~b})$. Cytosol $(200 \mu \mathrm{l})$ was added to $100 \mu \mathrm{l}$ buffer solution of ligand. $\left[{ }^{3} \mathrm{H}\right] \mathrm{Cortisol}$ and $\left[{ }^{3} \mathrm{H}\right]$ dexamethasone were used at final concentrations of 6 and $15 \mathrm{nM}$, either in the absence or presence of 100 -fold molar excess of unlabelled ligand. Incubations were carried out for various periods of time, up to $30 \mathrm{~h}$. The incubations were terminated by the addition of $400 \mu \mathrm{l}$ dextran-coated charcoal suspension $(6.25 \mathrm{~g}$ charcoal $/ 1,0.625 \mathrm{~g}$ dextran/1). The samples were centrifuged at $1000 \mathrm{~g}$ for $10 \mathrm{~min}$ to remove unbound steroid.

$\left[{ }^{3} \mathrm{H}\right]$ Cortisol-binding assay. Cortisol-receptor-binding capacity and binding characteristics in muscle cytosol were investigated as described by Vernon et al. (1974). Various concentrations $(0 \cdot 5-60 \mathrm{nM})$ of $\left[{ }^{3} \mathrm{H}\right]$ cortisol were used. An incubation period at $4^{\circ}$ of $24 \mathrm{~h}$ was employed to ensure maximum exchange between any intracellular endogenous cortisol and labelled ligand (Braunsberg \& Hammond, 1980). Corrections for non-specific binding and Scatchard analysis were carried out as described by Chamness \& McGuire (1975).

$\left[{ }^{3} H\right]$ Dexamethasone-binding assay. Muscle samples were homogenized $(1: 2, \mathrm{w} / \mathrm{v})$ in $5 \mathrm{~mm}$-Tris- $\mathrm{HCl}$ buffer (pH 7.4) containing $1 \mathrm{~mm}$-EDTA, $0.1 \mathrm{~mm}$-dithiothreitol, $10 \mathrm{~mm}$ sodium molybdate, $100 \mathrm{~g}$ glycerol/1. The homogenate was centrifuged (105000 $\mathrm{g}$ for $60 \mathrm{~min})$ and the supernatant fraction used as cytosol. Cytosol $(200 \mu \mathrm{l})$ was incubated with $100 \mu \mathrm{l}$ of a buffer solution of ligand $\left(0 \cdot 6-20 \mathrm{nM}-\left[{ }^{3} \mathrm{H}\right]\right.$ dexamethasone) either in the presence or absence of a 100-fold excess of unlabelled ligand. Incubations were also carried out to determine total binding by substituting $200 \mu \mathrm{l}$ buffer for cytosol. Incubations were carried out at $4^{\circ}$ for $24 \mathrm{~h}$. Dextran-coated charcoal suspension (6.25 g charcoal $/ 1,0.625 \mathrm{~g}$ dextran $/ 1$; $0.4 \mathrm{ml}$ ) was added to the cytosol incubations; these samples were incubated at $4^{\circ}$ for $20 \mathrm{~min}$, centrifuged $(1000 \mathrm{~g}$ for $5 \mathrm{~min}$ ) and $0.5 \mathrm{ml}$ of the supernatant fraction counted to determine protein-bound ligand. Buffer $(0.4 \mathrm{ml})$ was added to the total count tubes and $0.5 \mathrm{ml}$ of the resulting solution counted.

Ligand specificity studies. These were carried out by the method of Snochowski et al. (1980a) using a final concentration of $6 \mathrm{nM}-\left[{ }^{3} \mathrm{H}\right]$ dexamethasone. The calculation of Logit $y$ and relative binding affinity were as described by Snochowski et al. (1980a).

\section{Statistics}

Results are expressed as mean values and standard errors of the mean. The significance of difference between treatment groups in the first trial was determined by analysis of 
variance. Treatments were considered not to be significantly different at $P>0.05$. In the second trial an analysis of variance was carried out on all receptor data using treatment, time and time-treatment interaction as variables.

The linear part of the Scatchard plot was determined by linear regression and the slope was tested against zero, the data obtained were not interpreted unless the slope was different with $95 \%$ confidence.

\section{RESULTS \\ Growth of animals}

The growth values (Table 1) show an increase in weight gain with anabolic treatment of 7 and $15 \%$ above that of the control with TBA and Zeranol respectively. There was no corresponding change in feed conversion efficiency. The increases in weight of the anabolic-treated animals compared with the controls, although not statistically significant (possibly reflecting the small sample size involved) were smaller than those seen in other studies with sheep (Sinnett-Smith et al. 1983a; Buttery \& Sinnett-Smith, 1984). Possibly this was due in part to the better growth of the control animals in the present study. The design of the second trial means that weight-gain measurements were meaningless.

\section{${ }^{3} \mathrm{H}$-labelled ligand binding}

The longissimus dorsi muscle was considered suitable for the receptor assays since the rapid post-mortem $\mathrm{pH}$ drop found in this muscle in some species (Snochowski et al. 1981) does not occur in sheep. In preliminary experiments the $\mathrm{pH}$ of the assay mixture was tested at various times throughout the assay and no significant deviation from $\mathrm{pH} 7.4$ was found.

A rapid rise in $\left[{ }^{3} \mathrm{H}\right]$ cortisol and $\left[{ }^{3} \mathrm{H}\right]$ dexamethasone binding was found, reaching equilibrium between 6 and $16 \mathrm{~h}$ of incubation (Fig. 1). There was no appreciable degradation of the ligand-receptor complexes at up to $30 \mathrm{~h}$ of incubation. A time-period of $24 \mathrm{~h}$ was chosen as the incubation period for the binding assays, since the receptor-steroid complex is stable for this time and also ample time is allowed for exchange of labelled ligand with any endogenous steroid which may be bound to cytoplasmic receptors.

The binding affinities relative to dexamethasone of various steroids for the glucocorticoid receptor (Fig. 2) showed that the two glucocorticoids tested had relatively high affinities whereas trenbolone had very little affinity for the receptor (see Discussion).

Analysis of $\left[{ }^{3} \mathrm{H}\right]$ cortisol binding and $\left[{ }^{3} \mathrm{H}\right]$ dexamethasone binding after correction for non-specific binding using Scatchard plots indicated the presence of a single class of binding sites for the ligand (see Figs. 3 and 4).

The mean maximum binding capacity $\left(B_{\max }\right)$ for cortisol of the control group was $0 \cdot 114$ (SE 0.020$) \mathrm{pmol} / \mathrm{mg}$ protein with a dissociation constant $\left(K_{d}\right)$ of 0.75 (SE 0.16$) \mathrm{nM}$. Only TBA treatment significantly $(P<0.01)$ reduced $B_{\max }(0.048$ (SE 0.005$) \mathrm{pmol} / \mathrm{mg}$ protein), although a non-significant reduction and a non-significant increase in $B_{\max }$ were found with restricted diet and Zeranol treatment respectively. With no treatment was $K_{d}$ significantly altered (Table 2).

Initially the $B_{\max }$ for dexamethasone in TBA-treated animals was reduced below that of control animals, although this reduction was not statistically significant $(P>0.05)$. No effect on $B_{\max }$ was observed with restricted diet and Zeranol treatments. Again the various treatments did not alter the $K_{d}$ from the value for the control animals (7.30 (SE 3.11) nM; Table 3). The only significant effect on the $B_{\max }$ for cortisol of skeletal muscle occurred in TBA-treated animals; however, this group of animals appeared to be the worst affected by the bleeding procedure necessitating the removal of four TBA-treated animals from the experiment. In order to verify that the reduction in $B_{\max }$ was due to a TBA effect and was 


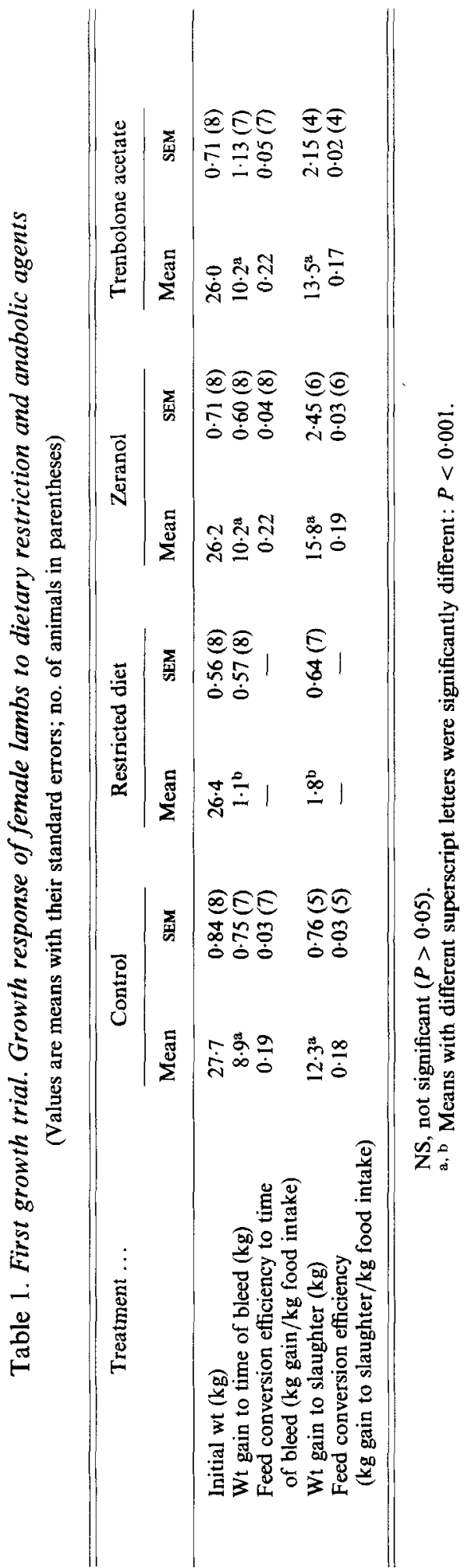



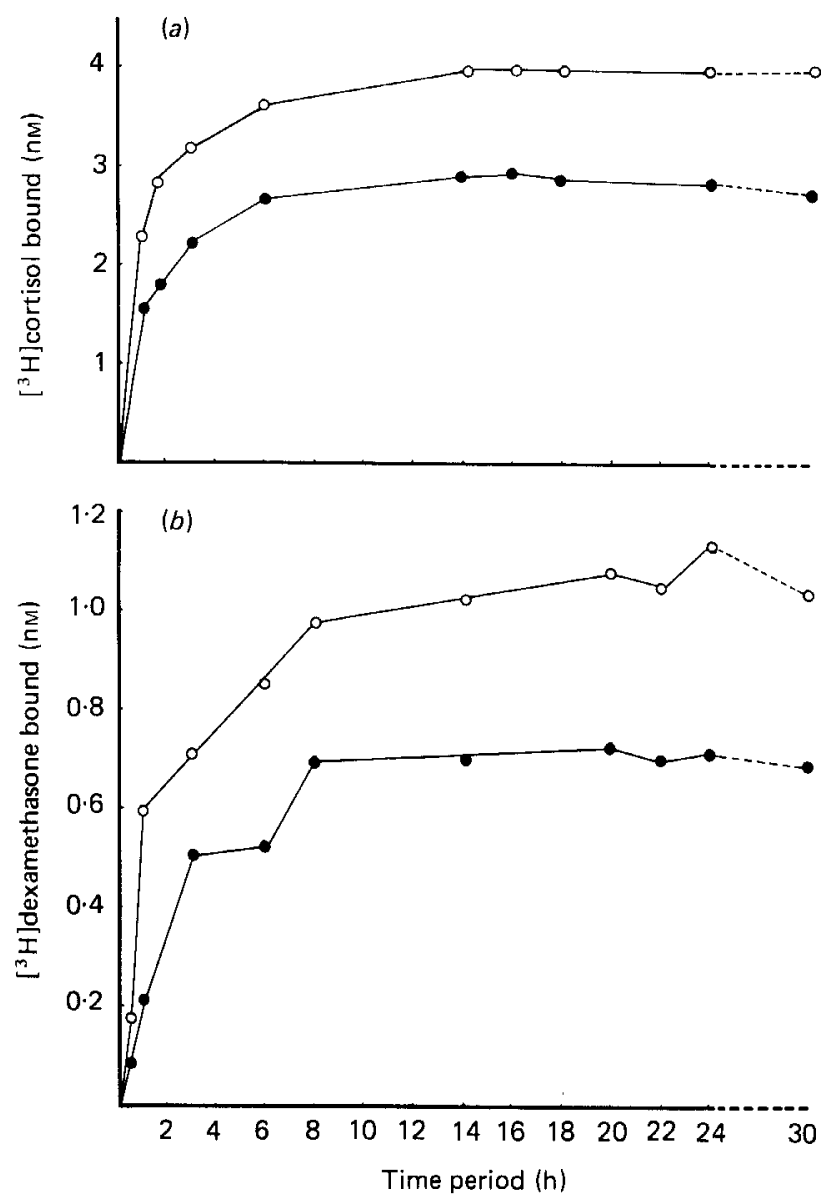

Fig. 1. Time course of binding of $(a)\left[{ }^{3} \mathrm{H}\right]$ cortisol and $(b)\left[{ }^{3} \mathrm{H}\right]$ dexamethasone to muscle receptors incubated at $4^{\circ}$. Each point represents the mean of two separate determinations. $(O), 15 \mathrm{nM} ;(\odot), 6 \mathrm{~nm}$.

not a result of the adverse effect of bleeding, the experiment was repeated using control and TBA-treated animals. The second trial confirmed the reduction in $B_{\max }$ of both cortisol and dexamethasone with TBA treatment (Tables 4 and 5). An analysis of variance of all values showed a significant reduction in $B_{\max }$ for both ligands $(P<0.01)$ and no significant change in $B_{\max }$ with time or time-treatment interaction. It appears, however, that the reduction in $B_{\max }$ occurred during the first $8 \mathrm{~d}$ after TBA treatment and persisted for at least 3 weeks (Tables 4 and 5).

\section{Hormone concentrations}

The concentrations of various hormone components are presented in Table 6. Although a slight non-significant reduction in total cortisol occurred in the TBA-treated group relative to the control, the reduction in transcortin concentration below that of the control in the TBA group resulted in a significant elevation $(P<0.05)$ in free cortisol. A similar relation between total, free and bound cortisol occurred in the restricted-diet group. In the Zeranol-treated group the slight elevation in total cortisol concentration was accompanied by a rise in transcortin concentration, so that free cortisol remained at the concentration found in the control animals. Insulin concentration did not vary significantly between the 


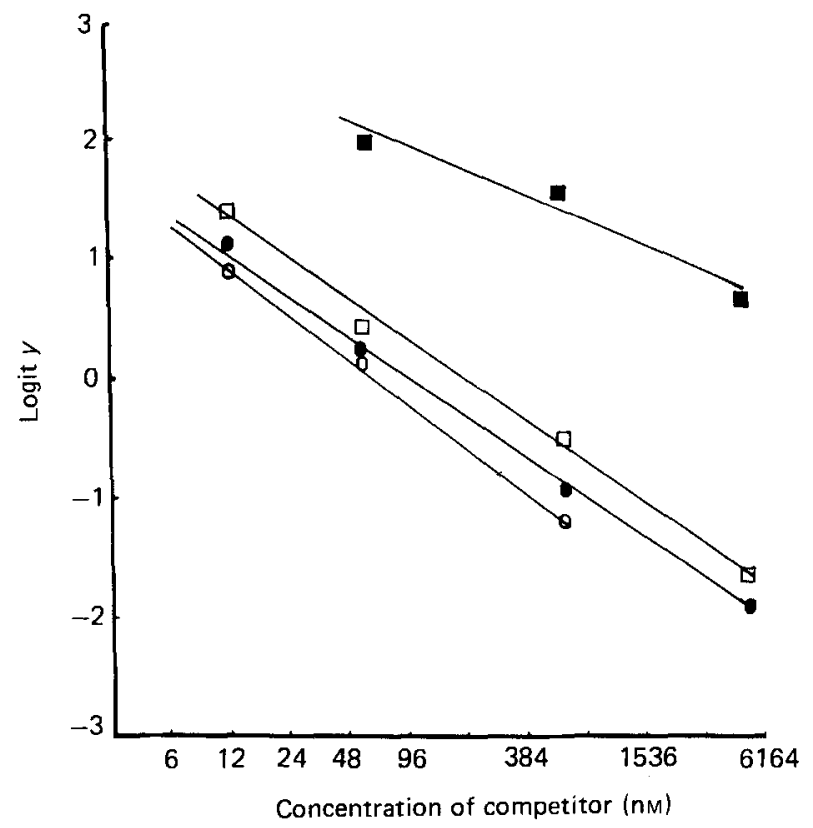

Fig. 2. Logit plots for various steroids competing for dexamethasone receptors in skeletal muscle. Each point is the mean for four separate determinations. Lines of best fit determined by linear regression. The calculated relative binding affinities were: dexamethasone $(O) 1$, triamcinolone $(O) 0.85$ (SE 0.16 ), cortisol ( $\square$ ) 0.51 (SE 0.25), trenbolone $(\square)<0.01$.

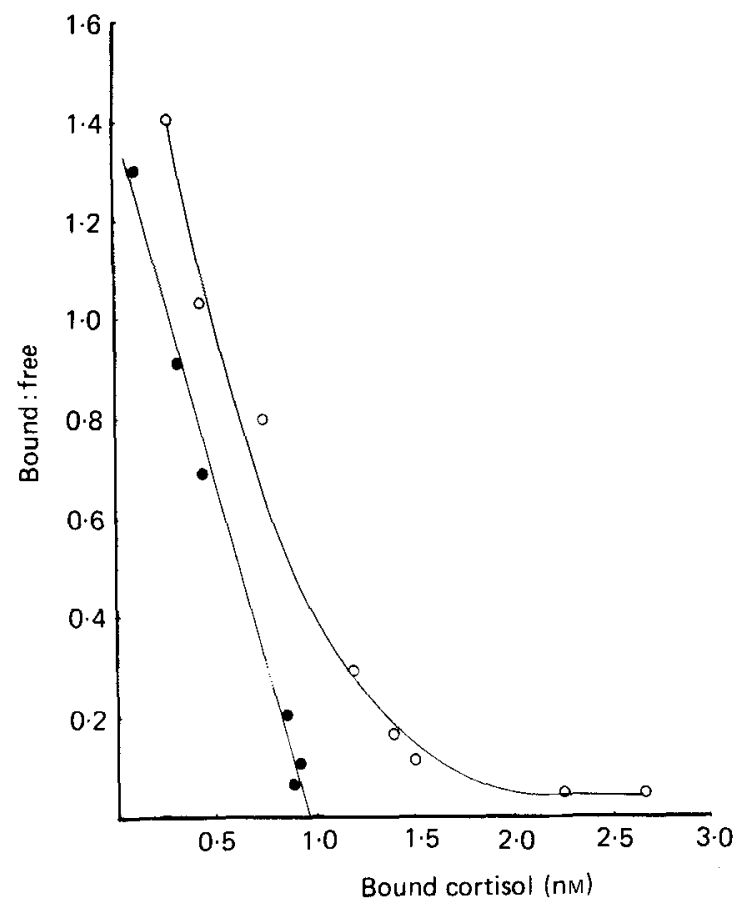

Fig. 3. Scatchard plot for binding of $\left[{ }^{3} \mathrm{H}\right]$ cortisol to skeletal muscle. A typical Scatchard plot for one of the control animals. Line for bound: free after correction for non-specific binding found by linear regression. The slope was tested for difference against zero and the values obtained were not interpreted unless the slope was different with $95 \%$ confidence. $(O)$, Total binding; (O), specific binding. 
Cortisol status and sheep growth
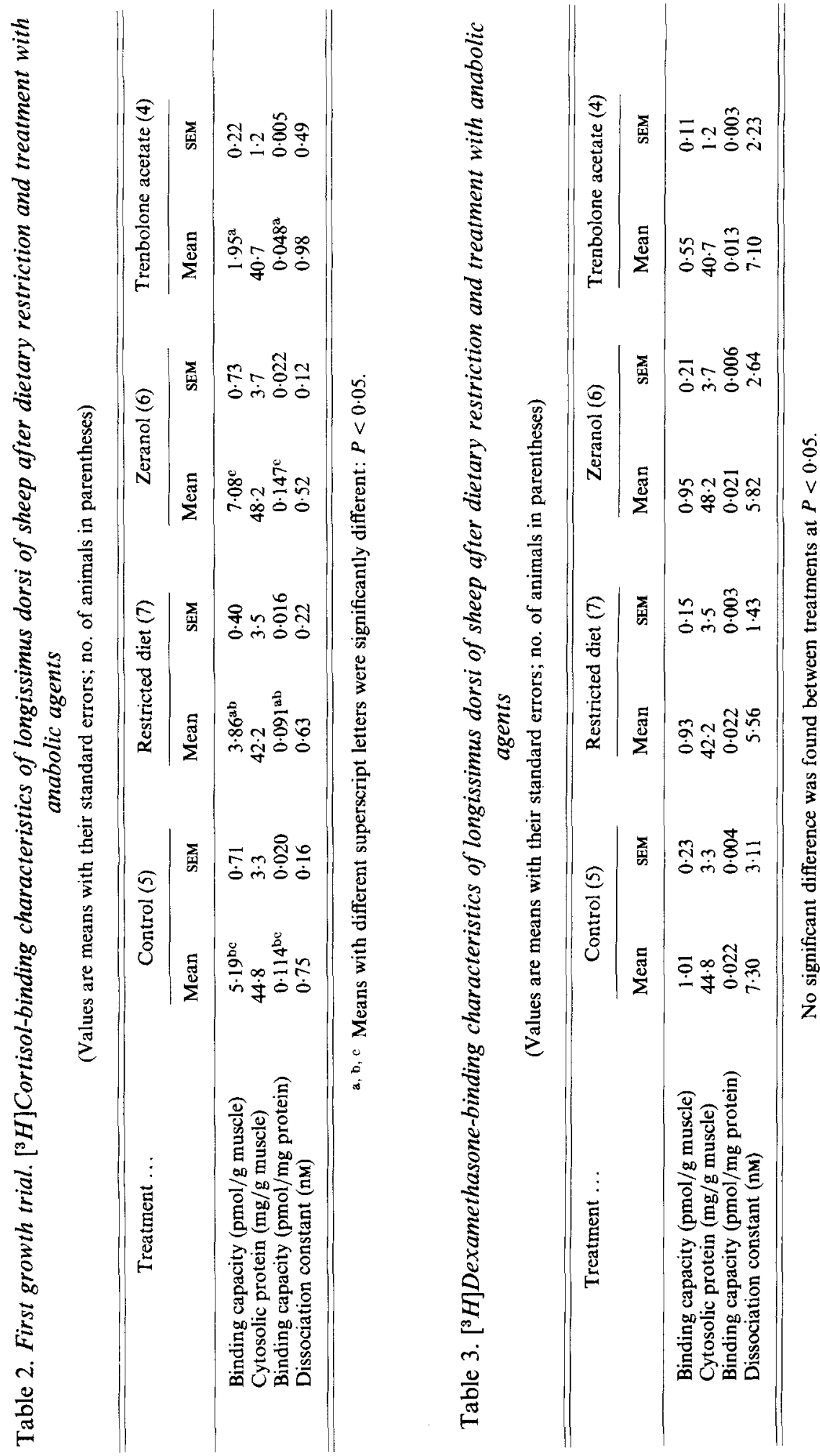

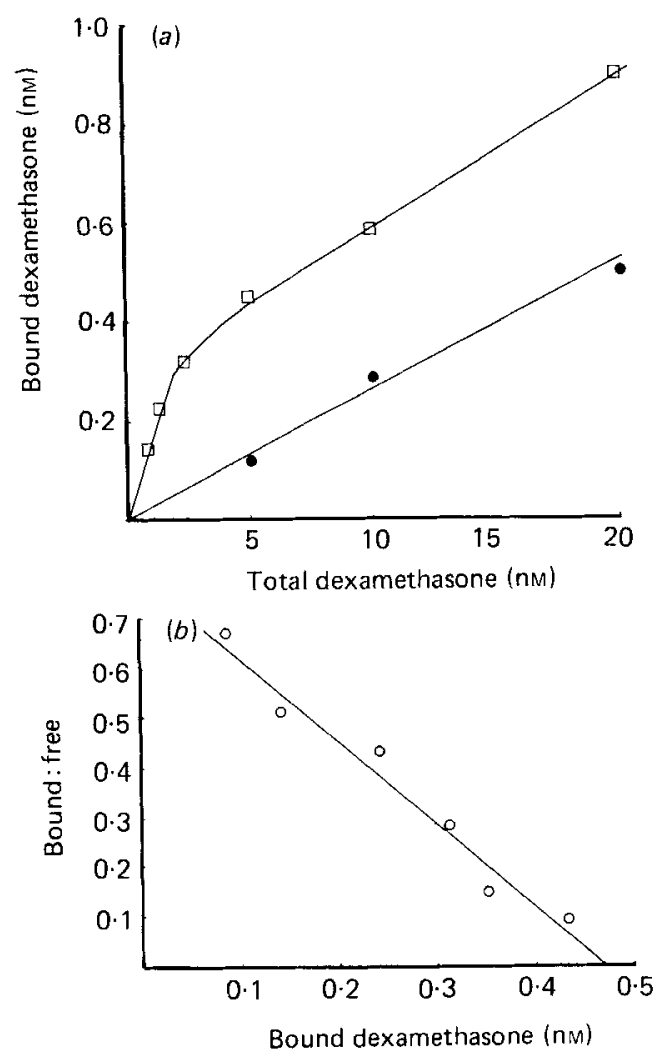

Fig. 4. Equilibrium analysis according to Scatchard of $\left[{ }^{3} \mathrm{H}\right]$ dexamethasone binding to sheep skeletal muscle cytosol. (a) ( $\square]$ ), total binding; (O), non-specific binding; $(b)(\bigcirc)$, specific binding. The slope of the Scatchard plot was determined by linear regression and was tested for difference against zero. The values obtained were not interpreted unless the slope was different with $95 \%$ confidence.

Table 4. Second growth trial. Changes in maximum binding capacity $\left(\mathrm{B}_{\text {max }}\right)$ of skeletal muscle for cortisol (pmol/mg protein) and changes in dissociation constant $\left(\mathrm{K}_{\mathrm{d}} ; n \mathrm{~m}\right)$ of receptors with time in sheep treated with trenbolone acetate (TBA)

(Values are means with their standard errors; no. of animals in parentheses)

\begin{tabular}{|c|c|c|c|c|c|}
\hline \multirow{2}{*}{$\begin{array}{c}\text { Period } \\
\text { after TBA } \\
\text { treatment (d) }\end{array}$} & & \multicolumn{2}{|c|}{ Control } & \multicolumn{2}{|c|}{ TBA } \\
\hline & & Mean & SEM & Mean & SEM \\
\hline \multirow[t]{2}{*}{$1(2)$} & $B_{\max }$ & 0.17 & 0.01 & $0 \cdot 11$ & $0 \cdot 02$ \\
\hline & $K_{d}^{\max }$ & 0.54 & 0.04 & 0.68 & 0.01 \\
\hline \multirow[t]{2}{*}{$8(2)$} & $B_{\max }$ & 0.13 & 0.01 & 0.06 & 0.03 \\
\hline & $K_{d}$ & 0.60 & 0.01 & 0.60 & 0.01 \\
\hline \multirow[t]{2}{*}{$15(4)$} & $B_{\max }$ & $0 \cdot 17$ & 0.01 & 0.07 & 0.02 \\
\hline & $K_{d}$ & 0.82 & 0.11 & 0.73 & $0 \cdot 14$ \\
\hline \multirow[t]{2}{*}{$22(2)$} & $B_{\max }$ & $0 \cdot 14$ & 0.01 & 0.05 & 0.01 \\
\hline & $K_{d}$ & 0.75 & 0.05 & 0.63 & 0.03 \\
\hline
\end{tabular}

Analysis of variance of all values showed a significant reduction in $B_{\max }$ with TBA treatment $(P<0.01)$ but no effect of time or time-treatment interaction $(P>0.05)$. 

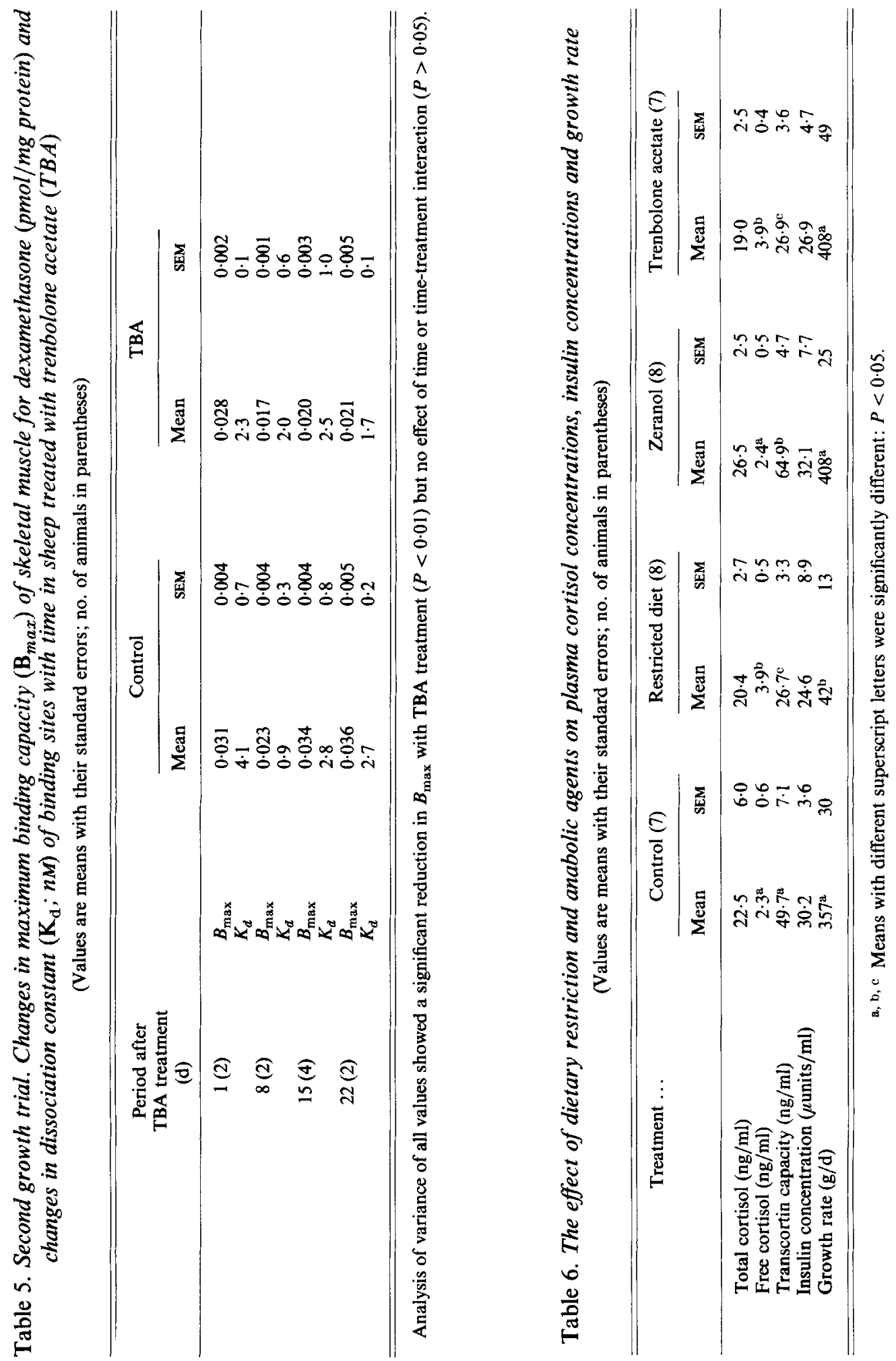
Table 7. First growth trial. Relations between various plasma hormone indices and individual growth rate $(\mathrm{g} / \mathrm{d})$ of animals

Total cortisol (C) $(\mathrm{ng} / \mathrm{ml})$

Free cortisol (F) (ng/ml)

Transcortin binding capacity (TB) $(\mathrm{ng} / \mathrm{ml})$

Insulin (I) $(\mathrm{IU} / \mathrm{ml})$

Total cortisol: insulin

Free cortisol: insulin

Transcortin: insulin

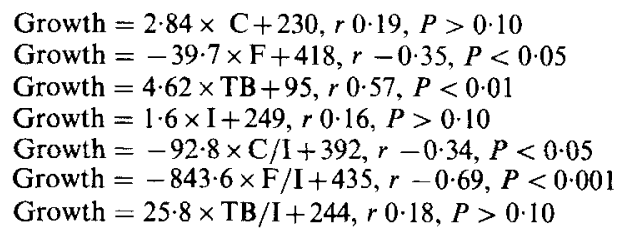

The growth rate of each animal was regressed $v$. the various hormone characteristics of that animal. All animals were included in the regression.

treatment groups. Comparisons between various hormone indices and growth rate for individual animals (Table 7) gave the following significant correlations: free cortisol $v$. growth $(r-0.35, P<0.05)$, transcortin concentration $v$. growth $(r 0.57, P<0.01)$, free cortisol:insulin $v$. growth $(r-0.69, P<0.001)$ and total cortisol:insulin $v$. growth $(r-0.34, P<0.05)$.

\section{DISCUSSION}

The work presented in the present paper is indicative of the presence of a relation between cortisol status in the sheep and growth, albeit complex, and a possible mode of action of the anabolic steroid TBA is suggested involving aspects of cortisol metabolism.

Early work on the glucocorticoid receptor in rat skeletal muscle was carried out using both $\left[{ }^{3} \mathrm{H}\right]$ cortisol and $\left[{ }^{3} \mathrm{H}\right]$ dexamethasone as the binding ligand. It was initially found that these two ligands were binding to separate and distinct sites (Mayer et al. 1974; Mayer \& Rosen, 1975). Although the muscle was perfused with saline $(9 \mathrm{~g}$ sodium chloride/1) it remained a possibility that binding of $\left[{ }^{3} \mathrm{H}\right]$ cortisol was due to contamination by blood proteins. Further work (Mayer et al. 1983) confirmed that binding had been due to contamination, although apparently cortisol and dexamethasone did bind to the same high-affinity receptor. Most other workers have used $\left[{ }^{3} \mathrm{H}\right]$ dexamethasone (e.g. Dahlberg et al. 1980; Snochowski et al. 1981). In the present study $\left[{ }^{3} \mathrm{H}\right]$ cortisol was also used since it was felt easier to equate changes in $B_{\max }$ of the endogenous hormone to physiological effects rather than with a synthetic compound. However, our results indicate some effect of blood contamination of cytosol on the observed $B_{\max }$ for cortisol. No effect of Zeranol and restricted-diet treatments was observed on the $B_{\max }$ for dexamethasone (Table 3 ). However, using cortisol an increase and reduction in $B_{\max }$ were observed with Zeranol and restricted-diet treatments respectively (Table 2). Clearly the change in $B_{\text {max }}$ in these treatment groups corresponded to changes in the transcortin concentration in the plasma (Table 6), indicating that transcortin contamination of the cytosol was influencing the apparent $B_{\max }$ for cortisol. Since plasma transcortin levels were roughly equivalent for both the TBA and restricted-diet groups (Table 6) one would expect a similar apparent $B_{\max }$; however, TBA-treated animals had a much lower apparent $B_{\max }$ for cortisol (Table 2). These results indicate that the reduction in apparent $B_{\max }$ for cortisol in TBA-treated animals was a result of a reduction in both contaminating transcortin (due to a reduction in plasma transcortin) and glucocorticoid receptor number.

Classical glucocorticoid receptors in skeletal muscle have a $K_{d}$ for $\left[{ }^{3} \mathrm{H}\right]$ dexamethasone of 3-10 nм (e.g. 6.9 nM Snochowski et al. 1981;6.7 nM Snochowski et al. 1980a; 5.1 nM average value from findings of Roth, 1974), whereas the affinity for natural glucocorticoids is usually lower, for example, the relative binding affinity (RBA) of corticosterone and 
cortisol for dexamethasone-binding sites in rat skeletal muscle is 0.46 and 0.11 respectively (Snochowski et al. 1980a). Our results confirm the presence of a glucocorticoid receptor with a $K_{d}$ for dexamethasone of $4.5 \mathrm{nM}$ (in control animals) and a similar RBA value for endogenous hormones. e.g. $\mathbf{0 . 5 1}$ for cortisol, as found by other workers (e.g. Snochowski et al. $1980 \mathrm{a}$ ). Dexamethasone binds only to cytosolic receptors and not contaminating blood proteins (Pugeat et al. 1981), thus the reduction observed in apparent $B_{\max }$ with TBA treatment (Tables 3 and 5) represents a reduction in the number of available cytosolic glucocorticoid receptors.

Since TBA-treated animals had a higher plasma-free cortisol concentration than that of control animals $(2.3$ v. $3.9 \mathrm{ng} / \mathrm{ml})$, it is possible that a higher intracellular cortisol concentration would result and consequently a greater number of binding sites would be occupied by endogenous cortisol, resulting in a lower apparent $B_{\max }$. If this were the case, however, one would expect a significant negative correlation between plasma free cortisol and $B_{\max }$, and no such correlation was found either within the TBA group or taking all animals. Furthermore, an increase in free cortisol in the diet-restricted group equivalent to that found in the TBA group did not cause a significant reduction in $B_{\max }$. TBA had little affinity for the glucocorticoid receptor (RBA $<1 \%$, Fig. 2); thus the reduction in $B_{\max }$ was taken to indicate a reduction in actual receptor number rather than TBA reducing the availability of binding sites by competing with the ${ }^{3} \mathrm{H}$-labelled ligand for the receptor.

Cortisol has previously been implicated as one possible mediator for the anabolic action of TBA (Buttery et al. 1978; Thomas \& Rodway, 1983 $a, b, c$ ) in rats and sheep by reducing plasma levels of glucocorticoids, possibly by reducing the response of the adrenals to adrenocorticotrophic hormone. The present study suggests that a further role of TBA in promoting growth may be the reduction in receptor sites for cortisol in skeletal muscle. TBA has been shown to reduce protein synthesis and degradation rates in female rats (Vernon \& Buttery, 1976), although this effect is not universal since castrate male rats show no response to TBA treatment (Vernon \& Buttery, 1978). Sinnett-Smith et al. (1983a) found a similar reduction in protein synthesis rate and degradation rate, as measured indirectly by cathepsin $\mathrm{D}(E C$ 3 .4 23.5) activity, in female lambs. The finding that TBA treatment in female lambs causes a reduction in the $B_{\max }$ of muscle for testosterone (Sinnett-Smith et al. $1983 \mathrm{~b}$ ) is consistent with a reduction in protein synthesis. The effects of glucocorticoids on muscle protein metabolism are not clear; certainly they cause a reduction in protein synthesis (Kelly \& Goldspink, 1982; Odedra \& Millward, 1982) and probabaly an increase in protein degradation (Kelly \& Goldspink, 1982; Santidrian et al. 1981). Thus a reduction in the $B_{\max }$ for cortisol would be consistent with a reduction in protein breakdown in TBA-treated animals.

A similar reduction in transcortin levels to that found in TBA-treated animals has been observed with other androgenic steroids, e.g. testosterone administration to female rats (Burton \& Westphal, 1972). This significant reduction in transcortin capacity below that of the control $(49 \cdot 7-26.9 \mathrm{ng} / \mathrm{ml}, P<0.01)$ caused an elevation of plasma free cortisol concentrations above those of the control animals $(2.3-3.9 \mathrm{ng} / \mathrm{ml}, P<0.05)$; total cortisol was also slightly reduced. These findings do not support the theory of Thomas \& Rodway $(1983 c)$ that reduction in plasma cortisol is one possible mode of action of TBA on growth, since free cortisol actually rises.

Similar results were observed for the animals on the restricted diet, i.e. a reduction in total cortisol but a greater reduction in transcortin concentration resulting in an elevation in free cortisol above that of the control.

Oestradiol and pregnancy (the effect of pregnancy is assumed to result from increased plasma oestradiol concentrations) cause an increase in both glucocorticoid and transcortin concentrations in a variety of species: rat (Seal \& Doe, 1965); human (Sandberg et al. 1966); 
rat, human, mouse, rabbit and guinea-pig (Seal \& Doe, 1963). In previous studies in the sheep, however, no effect of oestradiol treatment or pregnancy on transcortin concentration has been found (Linder, 1964; Paterson \& Hills, 1967). Nevertheless, in the present study treatment with the oestrogenic agent Zeranol showed a similar effect to that found in other species, i.e. a rise in glucocorticoid and transcortin concentrations resulting in no increase or very slight increase in free glucocorticoid. This rise in plasma transcortin concentration probably accounts for the rise observed in the $B_{\max }$ for cortisol in skeletal muscle (Table 2 ). The $B_{\max }$ for dexamethasone was unchanged from control values in Zeranol-treated animals (Table 3), as was the $K_{d}$, indicating no effect of Zeranol treatment on skeletal muscle glucocorticoid receptors.

Our findings thus show no effect either on free cortisol in the plasma or on the muscle binding of glucocorticoid in Zeranol-treated sheep. We therefore suggest that there is no observable involvement of the glucocorticoids in the growth-promoting action of Zeranol in the sheep. We are still unable to come to any conclusion on the mode of action of Zeranol except to say that its effects on cortisol status are quite different from those of TBA, again suggesting that there are several routes by which growth may be stimulated.

Our findings showed no significant change $(P>0.05)$ in plasma insulin concentration between treatments. Previous work has also shown no change in insulin with TBA treatment (Galbraith, 1980; Donaldson et al. 1981), whilst Zeranol treatment has been shown to increase insulin concentration (Sharp \& Dyer, 1970; Wangness et al. 1981).

Previous studies attempting to correlate glucocorticoid concentration with growth rate have not met with success (Keenan et al. 1968; Purchas et al. 1980), probably because total cortisol rather than free cortisol was used. The first study to show a significant negative correlation between free cortisol and growth rate in sheep was by Barnett \& Star (1981); however, as was stated earlier, this was in a complex situation involving recently parous sheep. We attempted to correlate various indices of glucocorticoid and insulin concentrations $v$. growth rate to the time of the bleed (Table 7). We appreciate that this is not an ideal situation since, as has been previously discussed, treatment with the anabolic agents affects glucocorticoid status in the blood, although neither TBA nor Zeranol is mediating its effect on growth via these changes. Nevertheless two interesting observations arise from these correlations (Table 7). First no significant relation between total cortisol and growth rate was found, although a stronger negative correlation between free cortisol and growth was observed. Interestingly, Barnett \& Star (1981) found, as we did, that the strongest correlation with growth rate was with transcortin capacity (Barnett \& Star (1981) value, $r 0.83$ ). We also found a significant relation between transcortin and free cortisol; as transcortin capacity rose, free cortisol fell $(r-0.52, P<0.05)$.

Second, we have found a highly significant relation between free cortisol:insulin values and individual animal growth rate $(r-0.69, P<0.001)$. It has previously been suggested (Tischler, 1981) that this ratio is important in affecting the protein balance in skeletal muscle. There is evidence from calculations on the values of Coward et al. (1977) that this relation is significant at physiological levels of hormones. A reciprocal linear relation $(r 0.85)$ between plasma corticosterone:insulin and total protein content of the gastrocnemius muscle in rats was found. Our findings also suggest that the antagonistic action of glucocorticoids and insulin on protein synthesis in skeletal muscle may be important not only in artificial circumstances (Odedra \& Millward, 1982; Odedra et al. 1982) but also in the normal growing animal.

The correlation for free cortisol:insulin and growth rate used all thirty animals. Examination of the TBA group as a whole suggests that these animals may be atypical, but inspection of Fig. 5 suggests that while this correlation is present in the TBA animals (e.g. correlation of free cortisol:insulin $v$. growth in these animals alone gives $r-0.81$, 


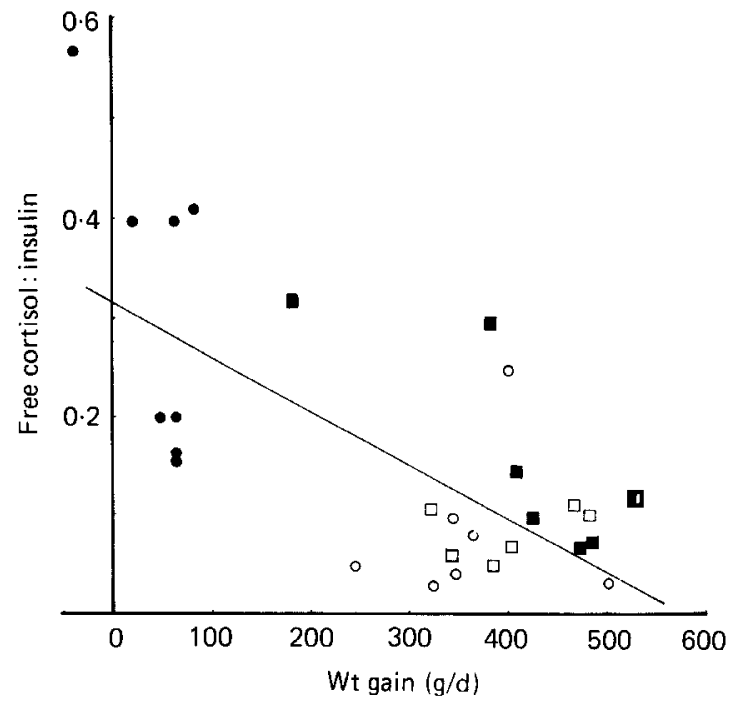

Fig. 5. Free cortisol:insulin and weight gain in individual animals. Treatments: $(0)$, control; ( $)$, restricted diet; $(\square)$, Zeranol; ( $\mathbf{\square})$, trenbolone acetate.

$$
y=-5.65 \times 10^{-4} x+0.32, \quad r-0.69 .
$$

$P<0.01)$ the numerical value of the ratio is increased. Possibly this reflects a modulation of cortisol metabolism by TBA.

We appreciate the problems involved in correlating across the four treatment groups but do suggest that the relation between free cortisol:insulin and growth merits further study, especially when growth is manipulated by diet alone.

The authors acknowledge the support of an SERC CASE Studentship in conjunction with Merck, Sharpe \& Dohme for P.M.S. and the assistance of Christine Palmer, Christine Essex, Judy Simpson and John Soar.

\section{REFERENCES}

Barnett, J. L. \& Star, M. L. (1981). Australian Journal of Agricultural Research 32, 487-496.

Braunsberg, H. \& Hammond, K. H. (1980). Journal of Steroid Biochemistry 13, 1133-1145.

Burton, R. M. \& Westphal, U. (1972). Metabolism 21, 253-276.

Buttery, P. J. (1983). Proceedings of the Nutrition Society 42, 137-148.

Buttery, P. J. \& Sinnett-Smith, P. A. (1984). In Manipulation of Growth in Farm Animals, pp. 211-232 [F. Roche and D. O'Callaghan, editors]. Boston: Martinus Nijhoff.

Buttery, P. J., Vernon, B. G. \& Pearson, J. T. (1978). Proceedings of the Nutrition Society 37, 311-315.

Chamness, G.C. \& McGuire, W. L. (1975). Steroids 26, 538-542.

Coward, W. A., Whitehead, R. G. \& Lunn, P. G. (1977). British Journal of Nutrition 38, 115-126.

Dahlberg, E., Snochowski, M. \& Gustafsson, J. A. (1980). Endocrinology 108, 1431-1440.

Donaldson, I. A., Hart, I. C. \& Heitzman, R. J. (1981). Journal of Veterinary Research 30, 7-13.

Feldman, D., Funder, J. W. \& Edelman, I. S. (1973). Endocrinology 92, 1429.

Gala, R. R. \& Westphal, U. (1965). Endocrinology 77, 841-851.

Galbraith, H. (1980). Veterinary Record 107, 559-560.

Giannopoulus, G. (1973). Journal of Biological Chemistry 248, 3876.

Keenan, D., McManus, W. R., Scoggins, B. A., Myers, K. \& Freer, M. (1968). Research in Veterinary Science 9 , 573-577.

Kelly, F. J. \& Goldspink, D. F. (1982). Biochemical Journal 208, 147-151.

Lange, W. \& Lindermann, E. (1972). Archiv für Tierernährung und Tierzucht 15, 171-188.

Linder, W. R. (1964). Journal of Endocrinology 28, 301-320.

Lowry, O. H., Rosenbrough, N. J., Farr, A. L. \& Randall, R. J. (1951). Journal of Biological Chemistry 193, 265. 
McGrath, J. A. \& Goidspink, D. F. (1982). Biochemical Journal 206, 641-645.

Markovic, R. D., Elsen, H. J., Parchman, L. G., Barnett, C. A. \& Litwack, G. (1980). Biochemistry 19, $4556-4564$.

Mayer, M., Finci, Z. \& Chaouat, M. (1983). Journal of Steroid Biochemistry 18, 19-22.

Mayer, M., Kaiser, N., Milholland, R. J. \& Rosen, R. (1974). Journal of Biological Chemistry 249, 5236-5240.

Mayer, M. \& Rosen, F. (1975). Israel Journal of Medical Science 11, 699-707.

Morris, R. (1978). Annals of Clinical Biochemistry 15, 178-183.

Odedra, B. R., Dalal, S. S. \& Millward, D. J. (1982). Biochemical Journal 202, 363-368.

Odedra, B. R. \& Millward, D. J. (1982). Biochemical Journal 204, 663-672.

Paterson, J. Y. F. \& Hills, F. (1967). Journal of Endocrinology 37, 261-268.

Pegg, P. J. \& Keane, P. M. (1969). Steroids 14, 705-716.

Pugeat, M., Dunn, F. J. \& Nisula, B. C. (1981). Journal of Clinical Endocrinology and Metabolism 53, 69-75.

Purchas, R. W. (1973). Australian Journal of Agricultural Research 24, 927-938.

Purchas, R. W., Burton, R. A. \& Kirton, A. H. (1980). Australian Journal of Agricultural Research 31, $221-232$.

Purchas, R. W., Pearson, A. M., Hofs, H. D. \& Tucker, W. A. (1971). Journal of Animal Science 33, 836-842.

Roth, G. S. (1974). Endocrinology 94, 82-90.

Sandberg, A. A., Rosenthal, H., Schneider, S. L. \& Slaunwhite, W. R. (1966). Steroid Dynamics, p. 1 [G. Pincus, T. Nakao and J. F. Tait, editors]. New York: Academic Press.

Santidrian, S., Marchon, P., Zhao, X. H.,Munro, H. R. \& Young, V. R. (1981). Growth 45, 342-350.

Seal, V. S. \& Doe, R. P. (1963). Endocrinology 73, 371-376.

Seal, V. S. \& Doe, R. P. (1965). Steroids 5, 827-841.

Sharp, G. D. \& Dyer, I. A. (1970). Journal of Animal Science 30, 1040.

Sinnett-Smith, P. A., Dumelow, N. W. \& Buttery, P. J. (1983a). British Journal of Nutrition 50, 225-234.

Sinnett-Smith, P. A., Palmer, C. A. \& Buttery, P. J. (1983b). IVth International Symposium on Protein Metabolism and Nutrition, vol. 2, pp. 77-80. Paris: INRA.

Snochowski, M., Dahlberg, E. \& Gustafsson, J. A. (1980a). European Journal of Biochemistry 111, 603-616.

Snochowski, M., Lundstrom, K. L., Dahlberg, E., Petersson, H. \& Edquist, L. E. (1981). Journal of Animal Science 53, 80-90.

Snochowski, M., Saartok, T., Dahlberg, E., Erikson, E. \& Gustafsson, J. A. (1980b). Journal of Steroid Biochemistry 14, 765-771.

Tait, J. F. \& Burstein, S. (1964). In The Hormones, vol. 5, pp. 441-557 [G. Pincus, K. V. Thimann and E. B. Astwood, editors]. New York: Academic Press.

Thomas, K. M. \& Rodway, R. G. (1983a). Animal Production 36, 529, Abstr.

Thomas, K. M. \& Rodway, R. G. (1983b). Journal of Endocrinology 98, 121-127.

Thomas, K. M. \& Rodway, R. G. (1983c). Proceedings of the Nutrition Society 42, 43 A.

Tischler, M. E. (1981). Life Sciences 28, 2569-2576.

Trenkle, A. \& Topel, D. G. (1978). Journal of Animal Science 46, 1604-1609.

Vernon, B. G. \& Buttery, P. J. (1976). British Journal of Nutrition 36, 575-579.

Vernon, B. G. \& Buttery, P. J. (1978). Animal Production 26, 1-9.

Vernon, R. G., Kopec, B. \& Fritz, I. B. (1974). Molecular and Cellular Endocrinology 1, 167-187.

Wangness, P. J., Olsen, R. F. \& Martin, R. J. (1981). Journal of Animal Science 52, 57-62. 